\title{
Numerical simulation of degradation of porous building materials caused by freeze-thaw cycles
}

\author{
Jiř̌́ Maděra ${ }^{1, *}$ and Jaroslav Kruis ${ }^{2, * *}$ \\ ${ }^{1}$ Department of Materials Engineering and Chemistry, Faculty of Civil Engineering, Czech Technical \\ University in Prague, Thákurova 7, 16629 Prague, Czech Republic \\ ${ }^{2}$ Department of Mechanics, Faculty of Civil Engineering, Czech Technical University in Prague, \\ Thákurova 7, 16629 Prague, Czech Republic
}

\begin{abstract}
Freeze-thaw cycles in porous building materials are studied in this contribution. Degradation and durability of many building materials as well as structural elements are tightly connected with the freeze-thaw cycles. The porosimetry curve and Gibbs-Thomson equation are used for estimates of volume changes caused by the freeze-thaw cycles. The volume changes are used in mechanical analysis based on the isotropic damage model. Numerical example documents the approach proposed.
\end{abstract}

\section{Introduction}

Degradation of porous building materials or structural elements made from such materials is commonly caused by freeze-thaw cycles. Numerical description or prediction of such cycles is not easy task because it requires several components, namely coupled heat and moisture transfer in porous material, realistic initial and boundary conditions, knowledge of the pore space and several material parameters. Therefore, many simplified indexes were introduced and they are used for simple and quick estimate of degradation [4]. Namely the Winter Index (WI), Modified Winter Index (MWI), Time of Frost (TOF), Amount of Frozen Water (AFW), etc.

In this contribution, more rigorous approach for determination of degradation of porous materials is introduced and described. It is based on coupled heat and moisture transfer which is accompanied by realistic initial and boundary conditions [3]. Second important component of the approach is the porosimetry curve which describes distribution of pore radius. Finally, volume changes caused by freeze-thaw cycles are used in mechanical analysis, where the isotropic damage model equipped with the Mazars norm is used.

\section{Coupled heat and moisture transport}

In this paper, attention is concentrated on porous building materials. Detailed list of models of coupled heat and moisture transport in concrete can be found in [2], models of coupled problems in soils are studied in [6]. For porous building materials, Künzel model [5] is very

\footnotetext{
*e-mail: madera@fsv.cvut.cz

**e-mail: jaroslav.kruis@fsv.cvut.cz
} 
popular. In paper [7], the original Künzel model was modified. The heat balance equation is in the form

$$
\frac{\mathrm{d} H}{\mathrm{~d} T} \frac{\partial T}{\partial t}=\operatorname{div}(\lambda \operatorname{grad} T)+L_{v} \operatorname{div}\left(\delta_{p} \operatorname{grad} p_{v}\right)
$$

where $H$ is the enthalpy density $\left(\mathrm{J} / \mathrm{m}^{3}\right), T$ is the temperature $(\mathrm{K}), t$ is the time $(\mathrm{s}), \lambda$ is the thermal conductivity $(\mathrm{W} / \mathrm{m} / \mathrm{K}), L_{v}$ is the latent heat of evaporation of water $(\mathrm{J} / \mathrm{kg}), \delta_{p}$ is the water vapour permeability (s) and $p_{v}$ is the partial pressure of moisture $(\mathrm{Pa})$. The mass balance equation has the form

$$
\varrho_{w} \frac{\mathrm{d} w}{\mathrm{~d} p_{v}} \frac{\partial p_{v}}{\partial t}=\operatorname{div}\left(\left(D_{w} \varrho_{w} \frac{\mathrm{d} w}{\mathrm{~d} p_{v}}+\delta_{p}\right) \nabla p_{v}\right)=\operatorname{div}\left(D_{g} \nabla p_{v}\right)
$$

where $\varrho_{w}$ is the water density $\left(\mathrm{kg} / \mathrm{m}^{3}\right), w$ is the volumetric moisture content $\left(\mathrm{m}^{3} / \mathrm{m}^{3}\right), D_{w}$ is the moisture diffusivity $\left(\mathrm{m}^{2} / \mathrm{s}\right), D_{g}(\mathrm{~s})$ is the global moisture transport function which was defined in [7] in the form

$$
D_{g}=A D_{w} \varrho_{w} \frac{\mathrm{d} w}{\mathrm{~d} p_{v}}+B \delta_{p}
$$

where coefficients $A, B$ are determined experimentally and the following condition has to be satisfied $A+B=1$.

\section{Freezing-thawing detection}

Some simplifications are taken into account for freezing and thawing detection. The pore space is described by porosimetry curve. For a given radius, $r$, the porosimetry curve indicates volume, $V$, of all pores with the radius smaller than $r$. The curve is described by a nondecreasing function, $V=p(r)$, to which an inverse function $r=p^{-1}(V)$ can be constructed. Volumetric moisture content has the form

$$
w=\frac{V_{w}}{V_{p}+V_{s}}
$$

where $V_{w}$ is the volume of water in pores, $V_{p}$ is the volume of pores and $V_{s}$ is the volume of the skeleton. It is assumed, the pores with smaller radius are filled before the pores with larger radius. For a given volumetric moisture content, $w$, obtained from the coupled heat and moisture transport, the radius of pores dividing the pore space into wet and dry parts can be obtained in the form

$$
r_{w}=p^{-1}(w)
$$

Freezing point depression depending on the radius $r_{w}$ is obtained from the Gibbs-Thompson equation

$$
\Delta T_{f}\left(r_{w}\right)=\frac{2 T_{c} \gamma_{s l} v_{l}}{\Delta h_{b} r_{w}}
$$

where $T_{c}(\mathrm{~K})$ is the coexistence temperature $\left(T_{c}=273.15 \mathrm{~K}\right), \gamma_{s l}\left(\mathrm{~mJ} / \mathrm{m}^{2}\right)$ is the surface free energy (interfacial tension) of the solid/liquid interface $\left(\gamma_{s l}=31.7 \pm 2.7 \mathrm{~mJ} / \mathrm{m}^{2}\right), v_{l}$ $\left(\mathrm{cm}^{3} / \mathrm{mol}\right)$ is the molar volume of the liquid $\left(v_{l}=18.02 \mathrm{~cm}^{3} / \mathrm{mol}\right)$ and $\Delta h_{b}(\mathrm{~kJ} / \mathrm{mol})$ is the melting enthalpy in the unconfined (bulk) state $\left(\Delta h_{b}=6.01 \mathrm{~kJ} / \mathrm{mol}\right)$. All quantities are taken at the bulk coexistence temperature. The freezing point has the form

$$
T_{f}=T_{c}-\Delta T_{f}\left(r_{w}\right)
$$


It is compared with the temperature obtained from the coupled transport and if the freezing point is greater, the appropriate radius to temperature $T$ is calculated from the GibbsThomson equation

$$
r_{T}=\frac{2 T_{0} \gamma_{s l} \nu_{l}}{\Delta h_{b}\left(T_{c}-T\right)}
$$

Clearly, the radius $r_{T}$ is smaller than $r_{w}$ and the volume of ice is obtained from the porosimetry curve in the form

$$
V_{f}=p\left(r_{w}\right)-p\left(r_{T}\right)
$$

The volumetric strain has in such a case the form

$$
\varepsilon^{V}=0,0905 V_{f}
$$

\section{Mechanics}

Mechanical response of porous building materials caused by freezing-thawing cycles is described with the help of isotropic damage model in this paper. This section briefly summarizes the model and numerical approach. Transport processes influence the mechanical response through the volumetric strains, $\varepsilon^{V}$, which occur in the constitutive law in the form

$$
\boldsymbol{\sigma}=\boldsymbol{D}\left(\boldsymbol{\varepsilon}-\left(\frac{1}{3} \varepsilon^{V}+\varepsilon^{T}\right) \boldsymbol{m}\right)
$$

where $\sigma$ is the stress vector, $\boldsymbol{D}$ is the stiffness of the the material, $\varepsilon$ is the strain vector, $\varepsilon^{T}$ is the temperature strain and $\boldsymbol{m}^{T}=(1,1,1,0,0,0)$ is an auxiliary vector. The temperature strain is assumed in the form

$$
\varepsilon^{T}=\alpha \Delta T=\alpha\left(T-T_{r}\right)
$$

where $\alpha$ is the coefficient of thermal expansion $(1 / \mathrm{K}), T$ is the temperature from the coupled heat and mass transport $(\mathrm{K})$ and $T_{r}$ is the reference temperature $(\mathrm{K})$.

Classical finite element method [1] is used for numerical solution, i.e. the displacement field, $\boldsymbol{u}$, is approximated in the form

$$
u=N d
$$

where $\boldsymbol{N}$ is the matrix of approximation functions and $\boldsymbol{d}$ is the vector of nodal unknowns. Strains have the form

$$
\varepsilon=\boldsymbol{B d}
$$

where $\boldsymbol{B}$ is the strain-displacement matrix. The problem is formulated in time increments which correspond to time steps used in the coupled heat and moisture transport. Summary of the numerical algorithm for linear problem is in Table 1.

Because damage mechanics is adopted, the algorithm is not linear and the displacement increment, $\Delta \boldsymbol{d}_{i+1}$, has to be obtained from equilibrium condition in the form

$$
f^{i n t}\left(d_{i}+\Delta d_{i+1}\right)+f_{i}+\Delta f_{i+1}=\mathbf{0}
$$

where $f^{i n t}(d)$ is the vector of internal forces which depends on attained displacements, $f_{i}$ is the vector of applied forces at time instant $t_{i}$ and $\Delta \boldsymbol{f}_{i+1}$ is the vector of increments of applied forces between times $t_{i}$ and $t_{i+1}$. Formula for its evaluation is in Table 1. Solution of (15) is done with the help of the Newton-Raphson method [1]. 
Table 1. Algorithm for linear time dependent mechanical problem.

\begin{tabular}{|l|l|}
\hline \multicolumn{2}{|c|}{ Iterate until $t \leq t_{\text {required }}$} \\
\hline increments of internal nodal forces & $\Delta \boldsymbol{f}_{i+1}=\int_{V} \boldsymbol{B}^{T} \boldsymbol{D} \boldsymbol{m}\left(\frac{\Delta \varepsilon_{i}^{V}}{3}+\Delta \varepsilon_{i}^{T}\right) \mathrm{d} V$ \\
increments of displacements & $\Delta \boldsymbol{d}_{i+1}=\boldsymbol{K}^{-1} \Delta \boldsymbol{f}_{i+1}$ \\
new vector of displacements & $\boldsymbol{d}_{i+1}=\boldsymbol{d}_{i}+\Delta \boldsymbol{d}_{i+1}$ \\
total strain increments & $\Delta \boldsymbol{\varepsilon}_{i+1}=\boldsymbol{B} \boldsymbol{d}_{i+1}-\boldsymbol{\varepsilon}_{i}$ \\
(previous total strain $\boldsymbol{\varepsilon}_{i}$ is stored) & \\
stress increments & $\Delta \boldsymbol{\sigma}_{i+1}=\boldsymbol{D}\left(\Delta \boldsymbol{\varepsilon}_{i+1}-\boldsymbol{m}\left(\frac{\Delta \varepsilon_{i}^{V}}{3}+\Delta \varepsilon_{i}^{T}\right)\right)$ \\
new stresses & $\boldsymbol{\sigma}_{i+1}=\boldsymbol{\sigma}_{i}+(\Delta \boldsymbol{\sigma})_{i+1}$ \\
\hline
\end{tabular}

Table 2. Material parameters of AAC.

\begin{tabular}{|l|l|}
\hline bulk density $\varrho\left(\mathrm{kg} / \mathrm{m}^{3}\right)$ & 289 \\
open porosity $\psi(\%)$ & 86.9 \\
specific heat capacity $c(\mathrm{~J} / \mathrm{kg} / \mathrm{K})$ & 1090 \\
water vapor diffusion resistance factor $\mu_{d r y}(-)$ & 15.61 \\
water vapor diffusion resistance factor $\mu_{\text {sat }}(-)$ & 6.17 \\
thermal conductivity $\lambda_{d r y}(\mathrm{~W} / \mathrm{m} / \mathrm{K})$ & 0.071 \\
thermal conductivity $\lambda_{\text {sat }}(\mathrm{W} / \mathrm{m} / \mathrm{K})$ & 0.548 \\
apparent moisture diffusivity $\kappa\left(\mathrm{m}^{2} / \mathrm{s}\right)$ & $7.02 \cdot 10^{-8}$ \\
Young modulus of elasticity $(\mathrm{GPa})$ & 30 \\
tensile strength $(\mathrm{MPa})$ & 1.5 \\
\hline
\end{tabular}

\section{Numerical example}

Numerical approach proposed is used in analysis of freezing water in a geometrically simple sample with sizes $0.1 \times 0.1 \mathrm{~m}$. The sample is assumed from autoclaved aerated concrete (AAC) with material parameters summarized in Table 2. Heat was removed on four finite elements in the center of the domain solved. It was realized as a negative heat supply. In order to see only the effect of ice growing, the thermal expansion was suppressed by zero coefficient of thermal expansion. All calculations were executed in the code SIFEL [8, 9]. Distribution of temperature on domain solved is depicted in Figure 1. Time evolution of the temperature in the center of the domain is depicted in Figure 2. With respect to the Gibbs-Thomson equation, freezing point depression was obtained and ice started to grow. Evolution of the damage parameter is depicted in Figure 3.

\section{Conclusion}

Numerical approach for description of freezing-thawing in porous building materials was introduced. It combines coupled heat and moisture transfer based on Künzel model, GibbsThomson equation and nonlinear mechanical analysis based on isotropic damage model with Mazars norm. The approach was used for analysis of simple sample which was exposed to 


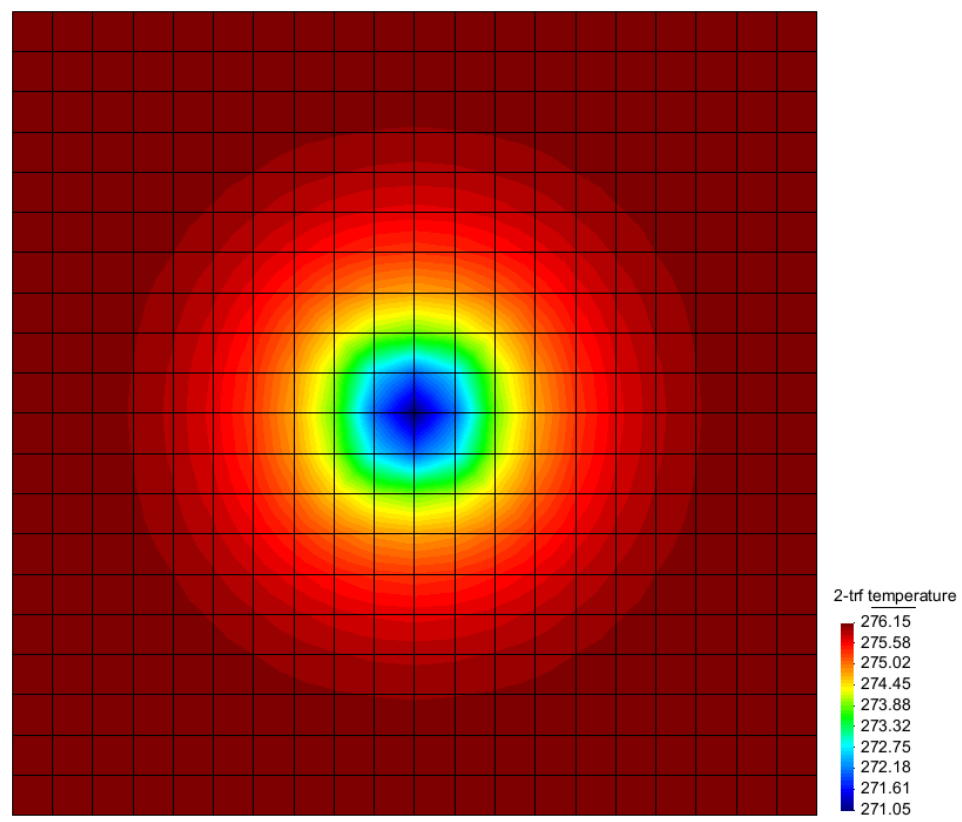

Figure 1. Temperature distribution in domain solved.

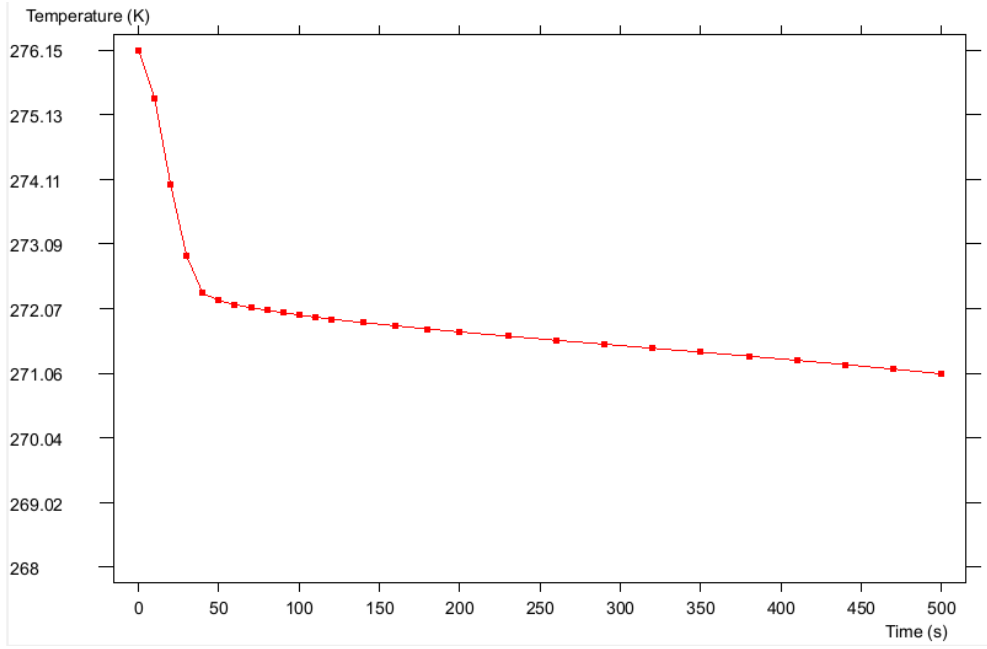

Figure 2. Evolution of temperature in the domain center in time.

change of temperature. Freezing of water led to ice growing which caused damage of the material because of volumetric changes.

This outcome has been achieved with the financial support of the Grant Agency of the Czech Republic, project No. 17-01365S. The financial support is gratefully acknowledged. 


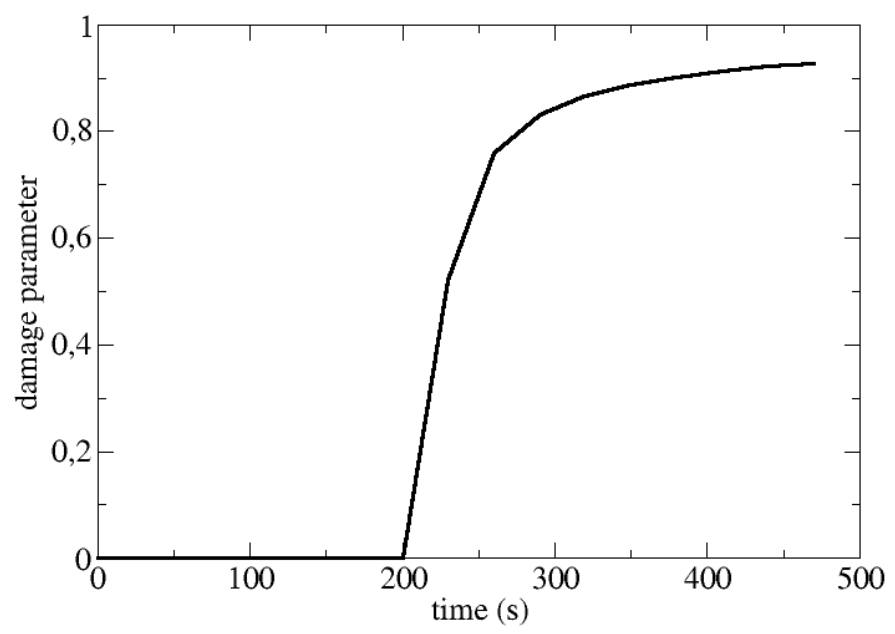

Figure 3. Evolution of damage parameter due to water freezing.

\section{References}

[1] Z. Bittnar, J. Šejnoha, Numerical Methods in Structural Mechanics (ASCE Press, Thomas Telford, New York, London, 1996).

[2] R. Černý, P. Rovnaníková, Transport Processes in Concrete (Spon Press, London, New York, 2002).

[3] K. D’urana, J. Maděra, R. Černý, Online climatic database for in-depth numerical analysis of building performance: Design of the code and example of application. In Proceedings of the 13th International Conference on Studies, Repairs and Maintenance of Heritage Architecture STREMAH 2013, Southampton: WIT Press, 2013, p. 245-256.

[4] J. Kočí, J. Maděra, M. Keppert, R. Černý, Cold Regions Science and Technology 135, 1-7 (2017).

[5] H.M. Künzel, Simultaneous Heat and Moisture Transport in Building Components (Fraunhofer Institute of Building Physics, Stutgart, 1995).

[6] R.W. Lewis, B.A. Schrefler, The Finite Element Method in the Static and Dynamic Deformation and Consolidation of Porous Media (John Wiley \& Sons, Chichester, England, 2000).

[7] V. Kočí, J. Kočí, J. Maděra, Z. Pavlík, X. Gu, W. Zhang, R. Černý, Journal of Building Physics 41(6), 497-520 (2018).

[8] J. Kruis, T. Koudelka, T. Krejčí, Efficient computer implementation of coupled hydrothermo-mechanical analysis, Mathematics and Computers in Simulations 80,8, 1578-1588 (2010).

[9] T. Koudelka, T. Krejčí, J. Kruis, Moderate Use of Object Oriented Programming for Scientific Computing In Proceedings of the Seventh International Conference on Engineering Computational Technology, Book Series: Civil-Comp Proceedings, Volume: 94, 2010. 